\title{
Conseqüências do Externalismo Behaviorista Radical ${ }^{1}$
}

\author{
Emmanuel Zagury Tourinho ${ }^{2}$ \\ Universidade Federal do Pará
}

\begin{abstract}
RESUMO - O artigo discute a proposta de Skinner para a ciência do comportamento, caracterizando-a como "externalista" (voltada para as relações do organismo com eventos que lhe são externos). Examina-se o discurso de Skinner sobre diferentes explicações para o comportamento, em obras de 1938, 1953 e 1990, a fim de indicar sua preocupação permanente com a definição das fronteiras entre análise do comportamento e (neuro)fisiologia. Apontam-se aspectos da elaboração skinneriana que a tornam insuficiente para sustentar uma declaração coerente sobre a autonomia de uma ciência do comportamento e procura-se ilustrar como essa dificuldade se reflete na literatura contemporânea da área.
\end{abstract}

Palavras-chave: behaviorismo radical; análise do comportamento; fisiologia do comportamento; eventos privados.

\section{Consequences of Radical Behaviorist Externalism}

\begin{abstract}
Skinner's approach to a science of behavior is discussed with reference to the concept of "externalism" (the search for relations between the organism and external events). Skinner's works, respectively, from 1938, 1953 and 1990 , whose discourses deal with different explanations of behavior, are examined in order to emphasize his persistent concern with drawing a clear distinction between behavior analysis and (neuro)physiology. Certain aspects of Skinner's writings, that seem to provide insufficient support for any definitive statement regarding the autonomy of a science of behavior, are highlighted along with resultant difficulties that have arisen in the literature of the field.
\end{abstract}

Key words: radical behaviorism; behavior analysis; physiology of behavior; private events.

Em um artigo sobre processos simbólicos e equivalência de estímulos, o filósofo Place (1995/1996) cita duas teorias que se sucederam na análise dos fenômenos usualmente identificados com a linguagem. A primeira, baseada nos modelos computacionais seriais, situa os símbolos e as operações com os mesmos (incluindo as regras que regulam estas operações) no cérebro do indivíduo. A segunda, baseada em modelos conexionistas, localiza no ambiente os mesmos eventos (ou o que corresponderia a eles em uma análise behaviorista). A primeira teoria é então caracterizada como internalista e a segunda como externalista. O behaviorismo radical é como essa segunda teoria: uma proposta externalista para a análise do comportamento dos organismos.

Ao postular que o comportamento é função da interação do organismo com variáveis que lhe são externas, o behaviorismo radical toma essa relação como a própria definição de comportamento. Se este é um princípio básico do projeto analítico-comportamental para a psicologia como ciência, sua adoção envolve um conjunto de decisões com respeito ao conhecimento produzido por outras áreas também interessadas no comportamento dos organismos, cujas conseqüências, apesar de reiteradamente discutidas, não se apresentam suficientemente demarcadas. Algumas destas consequiências serão examinadas a seguir, a partir do problema

1 Uma versão anterior deste trabalho foi apresentada no VI Encontro da Associação Brasileira de Psicoterapia e Medicina Comportamental, Santos, 1997. Trabalho parcialmente financiado pelo CNPq (Processo 301163-95-2).

2 Endereço: Rua Boaventura da Silva, 1251, Ap.1402. Umarizal. CEP: 66060-060 Belém - PA. E-mail: tourinho@amazon.com.br. da relação entre a análise do comportamento e a fisiologia. Além de defender a pertinência do conceito de externalismo para a caracterização do programa de Skinner para a psicologia, este artigo pretende argumentar brevemente que: (a) o recorte skinneriano se constrói a partir de uma tensão permanente com a fisiologia e as neurociências; e (b) este confronto dá origem a um conjunto de preocupações não equacionadas, seja no âmbito das formulações teórico-filosóficas, seja no campo da aplicação; (c) como resultado, não há consenso sobre a extensão com que o analista do comportamento pode se confinar ao seu próprio nível de análise do fenômeno comportamental.

\section{Externalismo, Ambientalismo e Contextualismo}

Em uma análise behaviorista radical, o conceito de comportamento, na medida em que diz respeito a uma relação, implica o reconhecimento de que as leis ou regularidades que lhe são pertinentes estão circunscritas, de um lado, pelos limites do próprio organismo e, de outro, pelos limites do universo com o qual o organismo interage. A modulação dessa relação pelas condições próprias de cada elemento é pressuposta, ao mesmo tempo em que se justifica uma investigação de suas regularidades à parte da especificação estrita daquelas condições. $\mathrm{O}$ conceito de externalismo pode cumprir a função de enfatizar a relação que interessa a uma ciência do comportamento.

Em vez de "externalismo", a expressão "ambientalismo" tem sido mais frequientemente usada pelos behavioristas para caracterizar o interesse pela relação dos organismos com as variáveis que lhes são externas. Entretanto, ela talvez não 


\section{E. Z. Tourinho}

seja a expressão que de modo mais eficiente indica o princípio salientado acima.

Ambientalismo significa atribuir à interação do organismo com o ambiente a determinação do comportamento. Este conceito seria suficiente para explicar o recorte de uma ciência do comportamento não fosse o fato de que é possível falar de um ambiente externo e de um ambiente interno (cf. Skinner, 1953/1965, 1974). O ambientalismo, nesse caso, deixa de ser uma referência explícita ao comportamento como relação do organismo com o que se situa a sua volta. Isto é, quando um behaviorista se apresenta como ambientalista, pode imediatamente ser lembrado de que o ambiente também se constitui pelo que está sob a pele de cada um. Aliás, isso chega mesmo a ser uma iniciativa do próprio behaviorista, para mostrar que não ignora, nem se isenta, dos problemas mais tradicionais da psicologia (cf. Skinner, 1974).

O conceito de ambiente interno não constitui uma proposta original de Skinner. Em 1930 (em uma edição revisada de um trabalho publicado originalmente em 1924), Watson já falava de uma dimensão interna do ambiente (ou "mundo de estímulos") afirmando que o "nosso 'ambiente'... não é conseqüentemente apenas um mundo de objetos, visões, sons e cheiros externos; ele é um mundo de objetos internos também - contrações de fome, distensões vesiculares, palpitações cardíacas, respiração rápida, mudança muscular e outros" (Watson, 1930/1970, pp. 74-75).

A observação de Watson se faz no contexto do reflexo como unidade de análise; o objetivo da psicologia behaviorista é "ser capaz de, dado o estímulo, prever a resposta ou, ao ver a reação acontecer, afirmar que estímulo provocou a reação" (Watson, 1930/1970, p. 18). A mera extensão do conceito ao sistema explicativo que se institui com o advento do operante como unidade de análise não pode ignorar que as relações estímulo-comportamento são agora formuladas de modo diverso e que a noção de processos discriminativos implica uma nova interpretação do conceito de ambiente.

Pode-se argumentar que o conceito de ambiente interno, no interior de uma análise operante, não implica uma independência do que está dentro do organismo na produção do comportamento (cf. Tourinho, 1997), mas os esclarecimentos que se tornam necessários a este respeito são tantos, que a expressão "ambientalismo" deixa de ser o melhor modo de falar do recorte skinneriano para uma ciência do comportamento. A palavra "externalismo", ao contrário, faz lembrar que a despeito de qualquer atenção que se dê ao que há dentro do organismo, a uma ciência do comportamento interessa identificar as relações com o que está fora dele.

Na verdade, a expressão "ambientalismo" parece ter sido consagrada mais como o contraponto behaviorista ao nativismo/inatismo veiculado em certos trabalhos da etologia (cf. Carvalho Neto, 1996; Hernstein, 1977; Smith, 1983). Neste caso, a expressão tem servido a alguns comentadores do behaviorismo para indicar que, para Skinner, não é na carga genética, mas na história de interação com o ambiente (seja ele interno ou externo), que se deve buscar a origem do comportamento dos organismos. Deve ser notado, porém, que Skinner rejeita ser identificado com esse "ambientalismo" (cf. Skinner, 1977, pp. 1007-1008), na medida em que não ignora o papel da filogênese na determinação do comportamento.

Além de "ambientalismo", também a expressão contextualismo é algumas vezes empregada na caracterização da ciência skinneriana. Esta expressão, porém, não especifica o recorte de uma ciência; ela esclarece apenas os supostos epistemológicos e/ou ontológicos envolvidos.

O behaviorismo radical é contextualista, em termos epistemológicos, no sentido de que vê suas leis como o resultado da interação dos analistas do comportamento com contingências especiais (físicas e sociais). É esta interação que delimita as possibilidades de uma ciência e a validade de suas leis.

Hayes, Hayes e Reese (1988) enumeram os seguintes aspectos "contextualistas" da análise do comportamento: a) o conceito de operante (que implica, necessariamente, uma relação); b) a adoção de um critério instrumental de verdade ou adequação; c) o papel do cientista na análise científica (interpretação do comportamento verbal científico como igualmente determinado por contingências de reforçamento; e d) a possibilidade de novidade (o reconhecimento da variabilidade).

No plano da ontologia, "uma vez que ela envolve suposições sobre a natureza da realidade, ... sobre o que existe e como o que quer que exista opera ou funciona" (Reese, 1993, p. 67), ser contextualista significa reconhecer que a realidade descrita pela ciência não é uma realidade independente do próprio comportamento do cientista.

Em termos de ontologia, a posição skinneriana não foi sempre consistente com uma perspectiva contextualista (Tourinho, 1996). A propósito deste problema, Barnes e Roche (1994) discutem a distinção citada por Reese (1993) entre uma ontologia mecanicista (que supõe existirem estímulos e respostas como entidades independentes) e uma epistemologia contextualista, que conviveriam contraditoriamente no behaviorismo radical. Barnes e Roche sustentam não tratar-se de uma contradição, mas de um paradoxo, na medida em que ontologia e epistemologia apresentam-se como "domínios diferentes" (e uma contradição só poderia ser estabelecida por comparação direta, o que, no caso de supostos pertencentes a domínios diferentes caracterizaria um "erro de categoria"). O que importa é observar que Barnes e Roche resolvem o paradoxo apontando que de uma epistemologia contextualista deriva-se necessariamente uma ontologia contextualista, na qual "a natureza fundamental do universo (ou realidade) existe como um evento comportamental, e não como uma realidade independente" (p. 167).

Portanto, o behaviorismo radical é contextualista ao reconhecer que seus princípios, suas leis e seus postulados sobre a realidade estão limitados pelas contingências às quais os analistas do comportamento estão expostos. Para além disso, ele é externalista no sentido de explicitar qual realidade pressupõe existir sob aquelas condições: relações ordenadas entre o organismo e mudanças nas condições à sua volta. 
Em outras palavras, o contextualismo informa qual o status do recorte com o qual a análise do comportamento opera. $\mathrm{O}$ externalismo explicita o próprio recorte, sistematicamente discutido por Skinner no conjunto de sua obra.

\section{Causas do Comportamento e o Recorte Behaviorista Radical}

Há várias ocasiões nas quais Skinner discute os possíveis determinantes do comportamento e apresenta o nível de análise de sua ciência para o fenômeno. Três destes momentos serão brevemente citados a seguir: 1938, quando Skinner estrutura primeiramente sua proposta para uma ciência do comportamento; 1953, quando sistematiza a extensão dos princípios dessa ciência ao comportamento humano; e 1990, quando justifica seu projeto de ciência a partir do modelo de seleção por conseqüências. O objetivo será indicar a preocupação revelada, neste trajeto, com a independência que uma ciência do comportamento deveria ter em relação à fisiologia.

\section{As causas do comportamento em 1938}

Em 1938, Skinner fala de sistemas primitivos de explicação do comportamento e de sistemas mais avançados. Os sistemas primitivos correspondem à explicação do comportamento por meio de um apelo a entidades abstratas (a respeito das quais Skinner não faz comentários adicionais neste texto), situadas para além do próprio organismo. Os sistemas mais avançados envolvem a atribuição de controle do comportamento a entidades situadas dentro do próprio organismo. Essas entidades internas são, na maioria das vezes, apresentadas como psíquicas ou mentais. Elas podem também envolver a opção pelo sistema nervoso como origem do comportamento, o que, por um lado, representaria um avanço (basicamente pela atribuição de dimensões físicas ao agente interno e, como decorrência, por torná-lo passível de investigação), mas, por outro, teria o efeito de desencorajar o interesse pelo comportamento como objeto de estudo em si mesmo. $\mathrm{O}$ apelo ao sistema nervoso para explicar o comportamento é visto como representando, muitas vezes, uma mera sofisticação dos modelos explicativos ficcionais, pois se faz sem o suporte de um conhecimento sistematizado a respeito e funciona para interditar a emergência e o desenvolvimento de uma ciência do comportamento. A restrição de Skinner (1938) é ao "uso primitivo do sistema nervoso como princípio explanatório que evita uma descrição direta do comportamento" (p. 4).

Skinner rejeita ambas as alternativas "primitivas" e "avançadas" e defende a proposta de uma psicologia como ciência do comportamento. Em uma tentativa de definir esse objeto, fala do comportamento como "aquela parte do funcionamento do organismo envolvida com $a$ ação sobre ou $o$ comércio com o mundo externo" (Skinner, 1938, p. 6, grifo adicionado).

A opção pela análise de relações organismo/mundo externo não impede Skinner de reconhecer a importância da neurologia enquanto ciência independente. Skinner dedica um capítulo do livro à discussão da relação entre as duas ciências (Skinner, 1938, cap. 12). Insiste que se trata de disciplinas complementares. Procura sustentar que os eventuais achados da neurologia não cancelam a pertinência de uma ciência que se ocupe de relações ordenadas entre ambiente e comportamento; ao contrário, "a própria noção de 'correlato neurológico' implica ... que há dois objetos de estudo independentes (respostas do organismo e o sistema nervoso) que devem possuir suas próprias técnicas e métodos e produzir seus respectivos dados" (Skinner, p. 423).

Além de apresentá-la como independente, Skinner defende que sua ciência do comportamento se estabeleça como uma ciência separada da neurologia, a despeito de qualquer eventual aproximação entre as duas. Para ele, os argumentos favoráveis ao desenvolvimento simultâneo das duas ciências e ao proveito que uma ciência do comportamento poderia tirar do conhecimento produzido pela neurologia "são muito menos convincentes do que sua aceitação geral na atualidade pareceria demonstrar" (Skinner, 1938, p. 424).

Resumindo, neste período de constituição de sua ciência, Skinner defende um recorte que relaciona o organismo ao que se situa no seu "mundo externo" e entende que muito do apelo então existente à neurologia era tão especulativo quanto as teorias mentalistas. Além disso, Skinner sequer se convence da possibilidade de usufruir de um conhecimento que viesse a ser construído sobre os aspectos (neuro) fisiológicos do comportamento. Em um comentário publicado cinqüenta anos depois, Skinner fala do livro de 1938 como uma "declaração de independência" em relação à fisiologia (cf. Skinner, 1988/1989, p. 129). No mesmo comentário, ainda que reconhecendo não ter escapado inteiramente da tradição internalista, ao formular conceitos como "reserva de reflexo", Skinner define o "behaviorismo radical" como " "a filosofia de uma ciência que trata do comportamento como objeto de estudo em si mesmo, à parte de explicações internas, mentais ou fisiológicas"' (Skinner, p. 122). O debate sobre a viabilidade de uma relação de independência e complementaridade entre as duas ciências, inaugurado já em 1938, mostrar-se-á, no entanto, muito mais perene do que seria de supor pelo entusiasmo de Skinner.

\section{As causas do comportamento em 1953}

Em Ciência e Comportamento Humano (Skinner, 1953/ 1965), Skinner contrasta o recorte de sua ciência com o que denomina de causas "populares" e causas "internas" do comportamento (humano).

Na categoria de causas populares, Skinner aborda a atribuição de causalidade a eventos com respeito aos quais nenhum tipo de confirmação é buscada e qualquer acidental coincidência é suficiente para produzir sua aceitação. Cabem, aqui, a astrologia e a numerologia, que correspondem aos sistemas primitivos apontados em 1938.

No item causas internas, Skinner justifica que toda ciência, em uma etapa preliminar, buscou as causas da ação no interior daquilo que estudava. Causas desse tipo são facil- 


\section{E. Z. Tourinho}

mente inventadas porque freqüentemente não podem ser confirmadas. Skinner as classifica em três grupos: as causas neurais, as causas psíquicas e as causas internas conceituais. As causas neurais são as que interessam diretamente à presente análise. Trata-se de explicações que apelam ao "cérebro" e aos "nervos". Skinner reconhece, neste momento, que "asserções sobre o sistema nervoso não são mais necessariamente inferenciais ou ficcionais" (Skinner, 1953/ 1965 , p. 28), como apontara em 1938. Apesar do reconhecimento, reitera que os achados da neurofisiologia não invalidam a proposta de uma ciência do comportamento. Ao contrário, como já sugerido em 1938, a própria neurofisiologia não se explica sem a referência às causas externas que produzem as respostas dos organismos. Quanto à possibilidade de serem identificadas condições neurais imediatamente antecedentes a instâncias comportamentais, Skinner comenta: "será descoberto, então, que estes eventos, por seu turno, são antecedidos por outros eventos neurológicos e estes por outros. Esta série nos levará de volta para os eventos fora do sistema nervoso e, finalmente, fora do organismo" (p. 28, grifo adicionado).

Skinner (1953/1965) mostra-se reticente, também, quanto à possibilidade de produção do comportamento pela alteração de condições neurofisiológicas antecedentes. Nesse caso, "as causas a serem procuradas no sistema nervoso têm ... utilidade limitada na predição e controle do comportamento específico" (pp. 28-29).

Dois aspectos da avaliação apresentada neste momento sobre o alcance das informações neurofisiológicas são importantes: a identificação de um conhecimento sistematizado sobre as bases neurofisiológicas do comportamento e a suposição de que a "inutilidade" das explicações fisiológicas decorre de sua limitação como base para a produção do comportamento.

Contrastando com as diferentes "causas" postuladas por teorias psicológicas, Skinner salienta nessa obra que sua ciência trabalha com a noção de "relação funcional", de acordo com a qual o comportamento é interpretado em termos de relações organismo-ambiente, que alteram a probabilidade do organismo agir de determinado modo em circunstâncias específicas. Trata-se, aqui, de um determinismo probabilístico, que reconhece a multideterminação do comportamento e contraria toda perspectiva de interpretação mecanicista. E, ainda, "estímulos" e "respostas" não são eventos independentes, mas definem-se no contexto das relações organismo-ambiente.

Após discutir as causas populares e as causas internas, Skinner (1953/1965) começa uma seção intitulada As Variáveis das quais o Comportamento é uma Função. Nesta seção, ele sugere que as variáveis independentes das quais uma ciência do comportamento se ocupa são aquelas localizadas "fora do organismo, em seu ambiente imediato e em sua história ambiental" (p. 31, grifo adicionado).

A partir desse texto, instauram-se dois problemas na discussão sobre o externalismo behaviorista radical. Primeiro, embora tenha sugerido que as variáveis independentes consideradas por uma ciência do comportamento estão fora do organismo, Skinner introduz o conceito de ambiente interno e aborda a possibilidade do comportamento ficar sob controle de variáveis independentes internas (cf. Skinner, 1953/ 1965, cap. XVII). Segundo, a crítica skinneriana à falta de instrumentalidade do conhecimento produzido no campo das neurociências comporta duas interpretações, uma em termos de limitação histórica e circunstancial (o conhecimento neurofisiológico é insuficiente até que especifique e permita a produção de condições particulares antecedentes ao comportamento), outra em termos de uma restrição permanente, inerente ao nível do recorte (dado que comportamento e condições corporais são produtos paralelos da interação organismo-ambiente, a especificação de um não promove a produção do outro).

\section{As causas do comportamento em 1990}

No artigo publicado em 1990, Skinner discute o projeto de constituição da psicologia como ciência do comportamento no contexto de seu modelo de seleção por consequiências. Segundo este modelo interpretativo, o comportamento humano é produto de três conjuntos de variáveis: as filogenéticas, as ontogenéticas e as culturais. Em todos os níveis, a produção do comportamento se dá regulada pelos princípios de variação e seleção. Se a variação pode, à primeira vista, ser localizada no próprio organismo (isso ocorre quando se fala da variação no que o organismo $f a z$; como comportamento diz respeito a uma relação, "variação do comportamento" já significa "variação em uma relação"), sua determinação, bem como a seleção de apenas algumas de suas instâncias são operadas por variáveis ambientais, que se diferenciam apenas com respeito a sua natureza ("naturais" ou sociais) e à temporalidade de sua ação. São essas diferenças que, por seu turno, vão indicar o lugar de cada ciência que lida com o comportamento. A etologia deve lidar com a filogênese; parte da antropologia deve se ocupar das práticas culturais; e a análise do comportamento, como legítima disciplina psicológica, deve se ater aos processos ontogenéticos, particularmente o condicionamento operante. As variáveis das quais o comportamento humano é função encontram-se, todas, no ambiente, atuando em níveis diferenciados na determinação do comportamento.

Novamente, Skinner procura dar conta da localização de seu sistema em relação à fisiologia; esta última, uma ciência que pode ser invocada para versões internalistas de psicologia. Cabe fazer, aqui, um parênteses. O artigo de 1990 é fortemente preocupado com o cognitivismo e com o internalismo que ele representa (não é sem motivo que o título do artigo é: Pode a psicologia ser uma ciência da mente?). $\mathrm{O}$ texto inicia e termina falando do cognitivismo e de seu apelo ao cérebro, quando o conceito de mente já não lhe dá suporte. Skinner busca não apenas apontar a fisiologia e a análise do comportamento como ciências independentes; reitera também que o sistema nervoso central é um nível insuficiente de explicação do comportamento, pelo menos para uma disciplina psicológica. Se a fisiologia tem um lugar reconhecido enquanto ciência que estuda o produto dos 
processos de variação e seleção, ela não pode assumir o status de explicação do comportamento.

Etologia, análise do comportamento e antropologia, enquanto ciências da variação e seleção, ocupam-se dos processos através dos quais os organismos são mudados, tornando-se mais provável que se comportem de determinados modos. A fisiologia não estuda esse processo. Ela pode especificar o funcionamento fisio-químico do organismo mudado, mas não o processo de mudança; a mudança é produzida de fora para dentro do organismo. Em resumo, "a fisiologia estuda o produto daquilo que as ciências da variação e seleção estudam a produção" (Skinner, 1990, p. 1208).

A solução cognitivista de apelar ao cérebro para restabelecer o internalismo na psicologia não teria, assim, consistência. $\mathrm{O}$ cérebro, como parte do corpo não pode explicar a mudança do próprio corpo. Ele é parte do que deve ser explicado. "O cérebro é parte do corpo e o que ele faz é parte do que o corpo faz. O que o cérebro faz é parte do que deve ser explicado" (Skinner, 1990, p. 1206).

Skinner percebe que a apropriação da neurofisiologia pelo cognitivismo moderno representa um projeto concorrente a sua proposta de ciência do comportamento. Contra este movimento, não invoca a carência de conhecimento ou sua falta de instrumentalidade. Ao contrário, busca na própria biologia, mais precisamente no modelo evolutivo de Darwin, os elementos para justificar a insuficiência dos modelos internalistas e a pertinência das ciências da variação e seleção.

\section{Conseqüências do Recorte Skinneriano}

Afinal, em que condições pode a ciência do comportamento confinar-se ao seu nível de análise do fenômeno comportamental, mantendo uma relação de independência para com a fisiologia e as neurociências? O que significa propriamente essa independência e o que deveria ser a base para a integração do conhecimento produzido nessas áreas? Apesar do indiscutível valor do conjunto da obra de Skinner para a constituição da psicologia como ciência do comportamento, sua posição sobre as relações análise do comportamento/fisiologia tem sido apontada como inconsistente (Reese, 1996a) e nenhuma interpretação alternativa foi até agora capaz de instaurar um consenso sobre o assunto entre os analistas do comportamento. Um intenso debate tem sido travado, alimentado pela crescente aceitação das neurociências e sua apropriação por novas versões de internalismo na psicologia. A apropriação é freqüentemente bem sucedida, na medida em que confere ao internalismo um status de cientificidade até então desconhecido em seu domínio. No cognitivismo moderno, o interno pode ter dimensões físicas e ser estudado pelos métodos experimentais.

O debate encontra suporte nas proposições de Skinner anteriormente citadas e revela a dificuldade em a partir delas derivar uma declaração definitiva sobre as fronteiras e a autonomia de uma ciência do comportamento. Pode-se ter um quadro razoável desse problema considerando os seguintes temas que aparecem na literatura:

\section{A possibilidade da análise do comportamento ignorar os processos fisiológicos}

A possibilidade da análise do comportamento simplesmente ignorar os processos fisiológicos foi recentemente defendida por Reese (1996a; 1996b) e reiterada (total ou parcialmente) por outros analistas do comportamento (Baer, 1996; Bullock, 1996; Donahoe, 1996; Poling e Byrne, 1996) que discutiram sua argumentação. A proposta não é a de que a análise do comportamento deve ignorar o conhecimento existente acerca dos processos fisiológicos, mas a de que ela pode deixar de considerá-lo sem ver reduzido seu poder explicativo. Como se trata de dois domínios diferenciados de investigação do comportamento, as "explicações fisiológicas não podem substituir explicações analítico-comportamentais" (Reese, 1996b, p. 87), mas apenas suplementar o conhecimento sobre o comportamento. Reese (1996a) acrescenta que a análise do comportamento pode ignorar os processos fisiológicos, mas não seus produtos. Ele também esclarece que isso não vale para outros ramos da psicologia, como a psicofarmacologia ou a psicofisiologia, que se ocupam exatamente da relação entre processos comportamentais e processos fisiológicos.

As declarações de Skinner no sentido da possibilidade da fisiologia contribuir com a análise do comportamento são aqui interpretadas como indicando simplesmente o reconhecimento de que ela (fisiologia) pode expandir o raio do conhecimento sobre o comportamento humano, justamente porque lida "com um domínio - o que está acontecendo dentro do organismo - com o qual a análise do comportamento não lida" (Reese, 1996b, p. 86).

Nesse caso, a complementaridade das duas ciências tem como parâmetro o domínio (externo/interno) de cada uma. Essa idéia de complementaridade está associada à noção de independência entre análise do comportamento e fisiologia (Reese, 1996b); contudo, deve ser observado que isso é diferente de se afirmar que os processos comportamentais independem de processos fisiológicos, pois esta suposição envolveria um paralelismo corpo-comportamento análogo ao paralelismo corpo-mente (Reese, 1996a). Assim, o analista do comportamento reconhece o substrato fisiológico do comportamento, mas sustenta que este substrato não precisa ser contemplado em sua explicação, pois é uma parte do organismo, cujas respostas podem ser explicadas a partir das relações com o ambiente externo.

Um modo diferente de postular a independência entre as duas ciências é argumentar que a análise do comportamento estuda uma relação (organismo/ambiente externo) cujos processos mediacionais (neurofisiológicos) são estudados pela fisiologia. É o que propõe Moore (1997), salientando duas questões que seriam de interesse para uma compreensão do comportamento, "a primeira é: como o comportamento de um organismo está funcionalmente relacionado a seu ambiente? A segunda é: como os sistemas neurofisiológicos do organismo medeiam aquelas relações funcionais?” (p. 242). (Observe-se que, neste trecho, Moore utiliza o conceito de 


\section{E. Z. Tourinho}

"comportamento" como equivalente à "resposta" o que, de todo modo, não invalida seu argumento). Para Moore, a análise do comportamento estaria ocupada da primeira questão; a segunda seria o domínio das neurociências.

A referência ao fisiológico como processos mediacionais já remete à discussão sobre a necessidade de especificação dessa mediação.

\section{A necessidade da análise do comportamento ver especificados os processos fisiológicos subjacentes ao reforçamento}

A tentativa de especificar os efeitos neurofisiológicos do reforçamento é uma iniciativa da abordagem biocomportamental, que se propõe a, desse modo, promover a integração entre a análise do comportamento e as neurociências (cf. Cavalcante, 1997; Donahoe \& Palmer, 1994), o que seria um modo de simultaneamente favorecer a aceitação da análise do comportamento, preservando-lhe a independência.

A abordagem biocomportamental é apresentada como uma tentativa de integrar à análise do comportamento uma compreensão dos eventos subcomportamentais (eventos intraorganísmicos inobserváveis), vencendo limitações de abordagens "metodológicas", segundo as quais a psicologia deve ater-se aos aspectos observáveis do fenômeno comportamental - estímulos e respostas públicos (o exemplo citado é o behavioriamo de Watson) - e de abordagens de "processo inferido", que inferem o componente interno inobservável a partir da observação dos eventos públicos no nível comportamental (o exemplo típico é o das teorias de processamento da informação) (Donahoe \& Palmer, 1994). Na abordagem biocomportamental, os eventos intraorganísmicos são objeto de investigação, mas a partir de análises experimentais diretas dos eventos fisiológicos que participam do fenômeno comportamental. Desse modo, a abordagem biocomportamental "suplementa a abordagem metodológica ... com a análise fisiológica de eventos intraorganísmicos observados" (Donahoe \& Palmer, p. 11, Figura 1.4), isto é, ela acompanha a abordagem de processo inferido no interesse pelos eventos intraorganísmicos, mas "não tenta inferir as características daqueles eventos de observações do ambiente e do comportamento unicamente" (Donahoe \& Palmer, p. 11, Figura 1.4).

A proposta de integrar ao estudo do comportamento a investigação dos processos subcomportamentais é considerada compatível com a proposta de Skinner para a ciência do comportamento. A compatibilidade é postulada a partir de três considerações de Skinner: a rejeição do critério de observabilidade direta (adotado pelo behaviorismo metodológico); a idéia de que referências a eventos inobserváveis são legítimas desde que com os conceitos forjados na investigação experimental; e o reconhecimento de que a fisiologia pode no futuro contribuir com a ciência do comportamento. Cumpre citar que estas são idéias veiculadas por Skinner em sua análise dos eventos privados, quando discute a possibilidade de uma ciência do comportamento lidar com fenômenos "sob a pele", inacessíveis a uma observação pública direta. Possivelmente, referindo-se ao texto de 1945 (Skinner, 1945), no qual Skinner apresenta pela primeira vez uma proposta de análise dos eventos privados, Donahoe e Palmer (1994) afirmam que "a idéia de que eventos microcomportamentais são parte de uma ciência do comportamento foi denominada por Skinner de behaviorismo radical" (p. 7).

Ao formular uma proposta para análise das intermediações neurofisiológicas do reforçamento, a abordagem biocomportamental o faz na forma de uma interpretação que se apóia em modelos computacionais designados redes adaptativas, e nos achados das neurociências, para simular alterações neurais produzidas por sequiências de interações organismo/ambiente. Como indicado pelo contraste com as abordagens metodológica e de processo inferido, a interpretação biocomportamental pretende estar baseada em princípios observados, nos níveis comportamental e subcomportamental. As simulações de alterações neurais usam "um programa de computador cujas instruções são informadas a partir de princípios derivados de análises experimentais do comportamento e da fisiologia. Através de sua operação, o programa implementa esses princípios e produz um resultado" (Donahoe \& Palmer, 1994, p. 57), que seria correspondente ao comportamento do organismo.

Sobre o recurso empregado pela abordagem biocomportamental para dar conta dos processos intraorganísmicos associados ao reforçamento, convém observar que a validade do uso de modelos computacionais para a análise de processos biológicos ainda está por ser firmada. Coutinho (1995) cita duas restrições básicas ao uso da linguagem da informática para explicar processos biológicos: primeiro, "há um grau de indeterminação biológica na visão darwiniana do processo de seleção, dado que o efeito do meio sobre o organismo opera aleatoriamente" (p. 324); segundo, "os processos biológicos são por demais complexos ... para poderem ser simulados por meio de processamentos paralelos como mecanismo de feedback" (p. 324).

Alguns autores que se referem especificamente à abordagem biocomportamental apontam um pseudoreducionismo (na medida em que se trata apenas de simulações aproximadas do que pode ocorrer ao nível fisiológico) à fisiologia (Reese, 1996a) e um possível retorno ao paradigma pavloviano (Shull, 1995), na medida em que alega que o efeito do reforçamento não é propriamente uma alteração na taxa da resposta reforçada, mas a seleção de relações estímulo-resposta. Entretanto, a abordagem é apresentada por seus formuladores como voltada para a integração entre análise do comportamento e (neuro)fisiologia e compatível com o externalismo skinneriano. A necessidade que a motiva tem sido caracterizada como mais "psicológica" do que "lógica" (cf. Donahoe, Burgos \& Palmer, 1993; Moore, 1997), na medida em que é pensada como necessária para promover a aceitação da teoria comportamental, do mesmo modo que a teoria darwiniana foi melhor aceita a partir da descoberta do DNA. Comparando as duas tradições teóricas, Donahoe e cols. argumentam que "Se um paralelo histórico for acatado, então, a aceitação de um princípio de seleção por reforçamento aguarda a identificação de seus mecanismos biológicos e o desenvolvimento de técnicas para interpretar suas implicações, que sejam mais rigorosas que interpretações verbais" (p. 19). 
Moore (1997) sumariza o caráter talvez mais político do que "psicológico" da proposta biocomportamental. Segundo ele, para certificar-se que não há uma aceitação ampla da análise do comportamento na comunidade científica, "basta comparar-se o número de analistas do comportamento que estão atualmente nas faculdades das universidades melhor classificadas e mais prestigiadas ao, digamos, número de psicólogos cognitivistas. O que pode ser feito para aumentar a aceitação da análise do comportamento?" (p. 244). O projeto da abordagem biocomportamental poderia ser visto como uma tentativa de prover aquela aceitação. "Se as pessoas estão mais inclinadas a aceitar a análise do comportamento quando os mecanismos neurais subjacentes que preenchem as lacunas forem especificados, então talvez devamos considerar a possibilidade de prover a especificação" (Moore, p. 244).

Talvez o paralelo com a teoria darwiniana não seja suficiente como argumento para a necessidade da análise do comportamento ver especificados os efeitos fisiológicos do reforçamento para chegar a uma melhor condição de aceitação. Se a motivação principal for realmente favorecer a adesão à proposta skinneriana para uma ciência externalista do comportamento, então, talvez a solução dependa também de uma análise das contingências que na atualidade não favorecem tal adesão, ou melhor, favorecem recortes alternativos para uma disciplina psicológica. Nesse caso, a abordagem biocomportamental pode estar espelhando de um modo particular uma problemática que transcende sua motivação e seu alcance.

\section{A necessidade da análise do comportamento aceitar a causação interna do comportamento}

Se a abordagem biocomportamental procura promover a integração, resguardando o externalismo skinneriano, o mesmo não ocorre com a tentativa de prover coerência para a proposta comportamental reconhecendo a possibilidade de causação interna do comportamento. Nesse caso, a inspiração vem da noção de ambiente interno e de seu emprego na análise dos eventos privados. Já na década de 70 , Zuriff (1979) apontava que Skinner reconhecia pelo menos dez causas internas do comportamento. Mais recentemente, Overskeid (1994) restabeleceu a polêmica, considerando, inclusive, que Zuriff foi tolerante para com as contradições de Skinner. Para Overskeid "não aceitar os eventos privados como causas iniciadoras do comportamento constitui uma inconsistência óbvia na teoria behaviorista radical, por razões teóricas e empíricas" (p. 38). Por outro lado, ainda segundo Overskeid, aceitá-los como causa representa exatamente aderir à proposta behaviorista radical.

O argumento de Overskeid (1994) é o de que qualquer sequiência causal é infinita e qualquer recorte arbitrário; portanto, se o evento privado é um elo da cadeia causal do comportamento, ele é uma causa legítima tanto quanto os elos externos. Para o behaviorismo radical, então, o critério para aceitação de um evento como causa do comportamento deve ser pragmático (admite-se como causa o que puder ser manipulado para produzir o comportamento). A solução de
Overskeid é pragmática como a de Zuriff (1979). Mas Zuriff apela ao problema da instrumentalidade para, na sua perspectiva de análise, justificar a não aceitação de causas internas. "Uma vez que a sequiência causal pára nas causas internas não manipuláveis, não é possível modificar o comportamento que elas controlam" (Zuriff, p. 7).

Já para Stemmer (1995), embora o critério pragmático deva ser evocado ("eventos internos são irrelevantes para uma análise funcional porque não contribuem para os objetivos pragmáticos de previsão e controle" - Stemmer, p. 353), na referência aos eventos privados deve-se diferenciar sua "força explicativa" de sua capacidade de propiciar a previsão e o controle do comportamento. A referência por Skinner aos eventos internos, nesse caso, é justificada para dar consistência explanatória ao sistema, mas sem admiti-los como causas do comportamento, exatamente porque sua função explicativa não se confunde com um valor preditivo.

Toda essa problematização acaba reduzindo-se a uma discussão sobre o valor instrumental das referências atuais aos eventos privados. É necessário indicar dois problemas nesse trajeto. Primeiro, no debate sobre a instrumentalidade das referências aos eventos internos, a possibilidade de manipulação está associada a sua especificação ao nível fisioquímico, como aponta Stemmer (1995). Retorna-se, desse modo, à relação análise do comportamento/fisiologia. Segundo (e associado ao primeiro), essa discussão tende a desviar a atenção do recorte originalmente proposto para uma ciência do comportamento. Novamente, confunde-se a defesa daquele recorte com o argumento de que explicações internalistas ainda são insuficientemente sólidas ou são incapazes de propiciar a produção do comportamento; como se um avanço no conhecimento do "mundo interno" tornasse as explicações dessa ordem aceitáveis. Flora e Kestner (1995) de certo modo atentam para o equívoco desse raciocínio, ao discutirem a tese de Overskeid (1994). Para eles, Overskeid está certo ao apontar que toda seqüência causal é infinita (embora o argumento seja inútil); entretanto, o recorte da cadeia causal, além de arbitrário, deve corresponder ao nível de análise pertinente à ciência que se está praticando. No caso da análise do comportamento, o elo interno não é apropriado porque não explica o que produziu a mudança no organismo (a explicação ficaria no mesmo nível das explicações mentalistas); quanto aos elos externos, seria inútil retroceder para além do que possibilita a explicação funcional do comportamento.

Pode-se admitir como teoricamente consistente a diferenciação do poder explicativo das referências aos eventos privados de sua capacidade preditiva (Stemmer, 1995), admitindo-as na interpretação do comportamento humano, mas buscando retroceder ao nível das variáveis externas ao organismo que, atuando sobre o mesmo, produzem aqueles eventos e os comportamentos. Não custa acrescentar, porém, que isto é insuficiente para encerrar qualquer debate sobre o assunto, particularmente porque mantém o impasse sobre quais critérios podem ser consistentemente empregados na definição das condições nas quais explicações internalistas deveriam ou poderiam ser acatadas. 
O que parece estar na origem das dificuldades em sustentar o recorte externalista quando se introduz o tema dos eventos privados é a própria imprecisão na definição desses eventos enquanto objeto de uma ciência do comportamento. Ao falar do evento privado como evento interno, inacessível, etc., Skinnner deixa de concebê-lo como uma relação (particularmente, uma relação indivíduo-cultura). O conceito de privado passa, então, a ser empregado para designar objetos diversos, como: (a) as condições corporais de um indivíduo; (b) os processos comportamentais correspondentes às circunstâncias nas quais se fala dos sentimentos ou pensamentos de alguém. Essa imprecisão permite que argumentos internalistas como o de Overskeid (1994) encontrem amparo nos próprios escritos skinnerianos. Entretanto, se pautada pelo princípio externalista e relacional, a definição de privacidade pertinente à análise do comportamento se torna incompatível com a noção de causação interna do comportamento.

\section{A possibilidade do analista do comportamento intervir sem recorrer de qualquer modo às alterações fisiológicas}

Quanto ao problema de recorrer ou não ao nível fisiológico no processo de intervenção, o apelo para que o psicólogo oriente sua ação para os componentes fisio-químicos de padrões comportamentais parece estar sendo fomentado mais pela atuação (sobretudo propagandística) das indústrias farmacêuticas e de seguros, enquanto surgem indicadores em uma direção contrária, favoráveis à intervenção tipicamente psicoterápica. Os interesses comerciais da indústria farmacêutica a aproximam da investigação dos processos comportamentais relacionados a "síndromes" particulares. Por exemplo, Silva (1997) afirma que uma das fontes do interesse crescente pela investigação experimental da ansiedade "vem da milionária indústria de tranquilizantes que está ininterruptamente sintetizando e testando novas substâncias" (p. 91). A comprovação da eficácia de certas substâncias na alteração da base química dos padrões comportamentais converte-se, em seguida, em argumento para campanhas que identificam em desequilíbrios orgânicos as "causas" dos problemas "psicológicos" e nos medicamentos a solução definitiva. A interferência das empresas de seguros, particularmente nos Estados Unidos, como salientado por Antonuccio, Danton e DeNelsky (1995), se dá na forma de ressarcimento de despesas com intervenções médicas em um percentual maior do que no caso de despesas com psicoterapia. Não se pode ignorar que o progresso das neurociências alimenta de forma consistente as iniciativas que sobrevalorizam a base (neuro)fisiológica do comportamento. O problema é especialmente relevante no caso da intervenção clínica, para a qual o modelo médico sempre se apresenta como forte concorrente, mas se estende a outras esferas.

Apesar de o debate, nesse campo de aplicação, não estar sendo fomentado por uma literatura skinneriana ou mesmo analítico-comportamental, é possível apontar nesta última certa especulação sobre o eventual valor preditivo da infor- mação fisiológica para a produção do comportamento na situação de intervenção. Considere-se, por exemplo, a declaração de Moore (1997) ao propor uma base pragmática para a complementaridade entre análise do comportamento e fisiologia: "uma vez que saibamos como estados internos fisiológicos estão funcionalmente relacionados ao comportamento, então, predições sobre o comportamento do organismo (ou mesmo intervenções pretendidas sob controle) podem basear-se em informações sobre o status atual daqueles estados internos" (pp. 242-243).

Se no nível da elaboração teórico-filosófica dos limites de uma ciência do comportamento é possível sustentar a independência em relação à fisiologia na delimitação de um programa de pesquisas, o reconhecimento da interdependência entre fenômenos comportamentais e fisiológicos sugere que as dificuldades são maiores quando se trata da análise aplicada do comportamento, e o marketing atual das neurociências e da farmacologia tenderia a favorecer uma interpretação de que neste nível não é possível ater-se apenas a uma abordagem externalista. Curiosamente, porém, enquanto a formulação e a aceitação do externalismo no plano conceitual-filosófico se mostram polêmicas, exatamente no campo da aplicação surgem elementos que favorecem a tese externalista.

Começa a ser questionada a idéia de que o terapeuta pode ou deve considerar o uso de medicamentos que alteram aspectos bioquímicos do sistema nervoso central, desenvolvidos a partir da descoberta das bases fisiológicas de alguns distúrbios. Em uma revisão da bibliografia sobre a efetividade de drogas e psicoterapia no tratamento da depressão, por exemplo, Antonuccio e cols. (1995) revelam que "as intervenções psicológicas, particularmente a terapia cognitivocomportamental, são pelo menos tão efetivas quanto a medicação no tratamento da depressão, mesmo que severa" (p. 581). Os autores acrescentam, para além disso, uma série de vantagens características do atendimento exclusivamente psicológico (por exemplo, maior tempo de permanência dos resultados e menores riscos médicos). Inúmeros outros indicadores na mesma direção são evidenciados de tempos em tempos e talvez merecessem uma repercussão mais ampla (ver, por exemplo, o artigo de Seligman, 1995, e o comentário de Kriegman, 1996).

Do ponto de vista do recorte analítico-comportamental, as dificuldades ilustradas no estabelecimento de fronteiras, que representem uma autonomia frente à neurofisiologia $\mathrm{e}$ uma rejeição coerente de recortes internalistas nela baseados, podem ser interpretadas como parcialmente decorrentes de uma formulação ainda insuficiente de problemas cruciais para a definição do campo e do alcance de uma ciência do comportamento. Se é verdade que as dificuldades citadas podem alimentar-se de afirmações nem sempre coerentes de Skinner sobre os limites de uma ciência do comportamento, é também preciso reconhecer que na própria obra de Skinner se encontram elementos a partir dos quais se pode organizar um quadro consistente de defesa do externalismo analítico-comportamental e da complementaridade entre análise do comportamento e (neuro)fisiologia. 
Do ponto de vista dos temas aqui discutidos, estudos que promovam uma reflexão mais sistemática sobre a noção de eventos privados (situando-os no campo das relações indivíduo-cultura) e sobre o critério instrumental de verdade (articulando-se com o recorte próprio de uma ciência do comportamento) podem representar uma contribuição adicional naquela direção.

\section{Referências}

Antonuccio, D.O., Danton, W.G. \& DeNelsky, G.Y. (1995). Psychotherapy versus medication for depression: Challenging the conventional wisdom with data. Professional Psychology: Research and Practice, 26, 574-585.

Baer, D. (1996). On the invulnerability of behavior-analytic theory to biological research. The Behavior Analyst, 19, 83-84.

Barnes, D. \& Roche, B. (1994). Mechanistic ontology and contextualistic epistemology: A contradiction within behavior analysis. The Behavior Analyst, 17, 165-168.

Bullock, D. (1996). Toward a reconstructive understanding of behavior: A response to Reese. The Behavior Analyst, 19, 75-78.

Carvalho Neto, M.B. (1996). Skinner e o papel das variáveis biológicas em uma explicação comportamental: uma discussão do modelo explicativo skinneriano a partir da contraposição desta proposta ao pensamento etológico de K. Lorenz. Dissertação de Mestrado, Universidade Federal do Pará, Belém.

Cavalcante, S.N. (1997). Abordagem biocomportamental: síntese da análise do comportamento? Psicologia: Reflexão e Crítica, 10, 263-273.

Coutinho, A.R. (1995). A questão da subjetividade: Justificativa de uma abordagem transdisciplinar baseada na pragmática. $\mathrm{Ca}$ dernos de Subjetividade, 3, 315-340.

Donahoe, J.W. (1996). On the relation between behavior analysis and biology. The Behavior Analyst, 19, 71-73.

Donahoe, J.W., Burgos, J.E. \& Palmer, D.C. (1993). A selectionist approach to reinforcement. Journal of the Experimental Analysis of Behavior, 60, 17-40.

Donahoe, J.W. \& Palmer, D.C. (1994). Learning and complex behavior. Boston/London: Allyn and Bacon.

Flora, S.R. \& Kestner, J. (1995). Cognitions, thoughts, private events, etc. are never initiating causes of behavior: Reply to Overskeid. Psychological Record, 45, 577-589.

Hayes, S.C., Hayes, L.J. \& Reese, H.W. (1988). Finding the philosophical core: A review of Stephen C. Pepper's World hypotheses: A study in evidence. Journal of the Experimental Analysis of Behavior, 50, 97-111.

Hernstein, R.J. (1977). The evolution of behaviorism. American Psychologist, 32, 593-603.

Kriegman, D. (1996). The effectiveness of medication: The Consumer Reports study. American Psychologist, 51, 1086.

Moore, J. (1997). Some thoughts on the S-R issue and the relation between behavior analysis and behavioral neuroscience. Journal of the Experimental Analysis of Behavior, 67, 242-245.

Overskeid, G. (1994). Private events and other causes of behavior: Who can tell the difference? Psychological Record, 44, 35-43.
Place, U.T. (1995/1996). Symbolic processes and stimulus equivalence. Behavior and Philosophy, 23(3) / 24(1), 13-30.

Poling, A. \& Byrne, T. (1996). Reactions to Reese: Lord, let us laud and lament. The Behavior Analyst, 19, 79-82.

Reese, H.W. (1993). Comments about Morris's paper. The Behavior Analyst, 16, 67-74.

Reese, H.W. (1996a). How is physiology relevant to behavior analysis? The Behavior Analyst, 19, 61-70.

Reese, H.W. (1996b). Response to commentaries. The Behavior Analyst, 19, 85-88.

Seligman, M.E.P. (1995). The effectiveness of psychoterapy: The Consumer Reports study. American Psychologist, 50, 965-974.

Shull, R.L. (1995). Interpreting cognitive phenomena: Review of Donahoe and Palmer's Learning and complex behavior. Journal of the Experimental Analysis of Behavior, 63, 347-358.

Silva, M.T.A. (1997). Modelos animais de ansiedade. Em D.R. Zamignani (Org.), Sobre comportamento e cognição (Volume 3, pp. 91-96). Santo André, São Paulo: ABPMC/ARBytes.

Skinner, B.F. (1938). The behavior of organisms. New York: AppletonCentury-Crofts.

Skinner, B.F. (1945). The operational analysis of psychological terms. Psychological Review, 52, 270-277/291-294.

Skinner, B.F. (1965). Science and human behavior. New York/London: Free Press/Collier MacMillan. (Originalmente publicado em 1953)

Skinner, B.F. (1974). About behaviorism. New York: Alfred A. Knopf.

Skinner, B.F. (1977). Hernstein and the evolution of behaviorism. American Psychologist, 32, 1006-1012.

Skinner, B.F. (1989). The behavior of organisms at 50. Em B.F. Skinner (Org.), Recent issues in the analysis of behavior (pp. 121-135). Columbus, Ohio: Merrill. (Originalmente publicado em 1988)

Skinner, B.F. (1990). Can psychology be a science of mind? American Psychologist, 45, 1206-1210.

Smith, T.L. (1983). Skinner's environmentalism: The analogy with natural selection. Behaviorism, 11, 133-153.

Stemmer, N. (1995). Explanatory and predictive roles of inner causes: A reply to Overskeid. Psychological Record, 45, 349-354.

Tourinho, E.Z. (1996). Behaviorismo radical, representacionismo e pragmatismo. Temas em Psicologia, 2, 41-56.

Tourinho, E.Z. (1997). Privacidade, comportamento e o conceito de ambiente interno. Em R.A. Banaco (Org.), Sobre comportamento e cognição (Volume 1, pp. 217-229). Santo André, São Paulo: ABPMC/ARBytes.

Watson, J.B. (1970). Behaviorism. New York: Norton Library. (Originalmente publicado em 1930, como edição revisada e ampliada de outra versão publicada em 1924).

Zuriff, G.E. (1979). Ten inner causes. Behaviorism, 7(1), 1-8. 